\title{
Computer Simulation and Verification of Adiabatic Temperature and Apparent Activity Energy of the NiO/Al Aluminothermic System
}

\author{
Yuepeng Song ${ }^{a, b, c}$, Zhu Yanmin ${ }^{a, c}$, Dongsheng Gao $^{c}$, Jing Guo ${ }^{a, b, c}$ and Hyoung Seop Kim ${ }^{b, *}$ \\ ${ }^{a}$ Mechanical and Electronic Engineering College, Shandong Agricultural University, Tai'an 271018, China \\ ${ }^{b}$ Department of Materials Science and Engineering, Pohang University of Science \\ and Technology, Pohang 790-784, Korea \\ ${ }^{c}$ College of Horticulture Science and Engineering, Shandong Provincial Key Laboratory of Horticultural Machineries \\ and Equipments Shandong Agricultural University, Tai'an 271018, China \\ (Received September 28, 2013; Accepted October 24, 2013)
}

\begin{abstract}
Recently, self-propagating high-temperature synthesis (SHS), related to metallic and ceramic powder interactions, has attracted huge interest from more and more researchers, because it can provide an attractive, energy-efficient approach to the synthesis of simple and complex materials. The adiabatic temperature $T_{\text {ad }}$ and apparent activation energy analysis of different thermit systems plays an important role in thermodynamic studies on combustion synthesis. After establishing and verifying a mathematic calculation program for predicting adiabatic temperatures, based on the thermodynamic theory of combustion synthesis systems, the adiabatic temperatures of the $\mathrm{NiO} / \mathrm{Al}$ aluminothermic system during self-propagating high-temperature synthesis were investigated. The effect of a diluting agent additive fraction on combustion velocity was studied. According to the simulation and experimental results, the apparent activation energy was estimated using the Arrhenius diagram of $\ln \left(\mathrm{v} / \mathrm{T}_{\mathrm{ad}}\right) \sim 1 / \mathrm{T}_{\text {ad }}$ based on the combustion equation given by Merzhanov et al. When the temperature exceeds the boiling point of aluminum $(2,790 \mathrm{~K})$, the apparent activation energy of the $\mathrm{NiO} /$ $\mathrm{Al}$ aluminothermic system is $64 \pm 14 \mathrm{~kJ} / \mathrm{mol}$. In contrast, below $2,790 \mathrm{~K}$, the apparent activation energy is $189 \pm 15 \mathrm{~kJ} /$ mol. The process of combustion contributed to the mass-transference of aluminum reactant of the burning compacts. The reliability of the simulation results was experimentally verified.
\end{abstract}

Keywords: Adiabatic temperature, Apparent activation energy, NiO/Al aluminothermic system, Computer simulation, Self-propagating high-temperature synthesis (SHS)

\section{Introduction}

A significant amount of attention has recently been focused on self-propagating high-temperature synthesis (SHS) related to metallic and ceramic powder interactions. Its underlying basis is the ability of highly exothermic reactions to be sustained in the form of a combustion wave. Because the temperature of the combustion wave can be extremely high, and the rate of wave propagation can be relatively rapid, the resulting chemical reactions can provide an attractive and energy-efficient approach to the synthesis of simple and complex materials including solid solutions, composite materials, and metastable phases [1]. The maximum reaction temperature and com- bustion velocity depend on the heat generation of reaction and mass and heat-transfer of the burning thermit compact. Therefore, the adiabatic temperature $T_{a d}$ and apparent activation energy analysis of different thermit systems plays an important role in thermodynamic studies on combustion synthesis.

Because of its strongly exothermic reactions, the $\mathrm{NiO} /$ $\mathrm{Al}$ aluminothermic system has usually been used in practice to produce many kinds of new materials (e.g., $\mathrm{Al}_{2} \mathrm{O}_{3}$ / $\mathrm{YAG} / \mathrm{YSZ}$ eutectic ceramic, transparent $\mathrm{Y}_{3} \mathrm{Al}_{5} \mathrm{Ol}_{2}$ (YAG), Ni-Al alloying, and composites) [2-11]. However, there is a significant discrepancy in the reported adiabatic temperature of the $\mathrm{NiO} / \mathrm{Al}$ aluminothermic system: one at $3,524 \mathrm{~K}$ [3] and another at 3,773 K [8]. Because of the

*Corresponding Author: Hyoung Seop Kim, TEL: +82-54-279-2150, FAX: +82-54-279-2399, E-mail: hyoungseopkim@gmail.com 
adiabatic temperature high above the boiling point of $\mathrm{Ni}$ products (reaching 3,156 K) in the $\mathrm{NiO} / \mathrm{Al}$ aluminothermic system, the Ni product should be in a gas phase after combustion, which is practically impossible. Furthermore, the apparent activation energy of this system has not been studied theoretically, which leads to many difficulties in researches on the combustion mechanism.

In this work, the thermodynamic parameters of the $\mathrm{NiO} / \mathrm{Al}$ aluminothermic system were collected first. Then the adiabatic temperatures of the $\mathrm{NiO} / \mathrm{Al}$ aluminothermic system were calculated based on the chemical thermodynamic theory. Combining the effects of a diluting agent $\mathrm{Al}_{2} \mathrm{O}_{3}$ mass fraction on the combustion velocity, and the product microstructure, thermodynamic parameters for the apparent activation energy can be obtained by calculating the relationship between adiabatic temperature and combustion velocity; as provided by Merzhanov et al. [4, 11]. In addition, the reliability of the calculation result was verified experimentally.

\section{Adiabatic Temperature Calculation and Combustion Velocity Inspection}

Adiabatic temperature, $T_{a d}$, is the temperature at which the enthalpy of the reaction heats only the products, and no heat energy is lost to the surrounding environment [12-14]. The assumption of the strongly exothermic reaction of the $\mathrm{NiO} / \mathrm{Al}$ aluminothermic system is tenable because of its highly exothermic reactions resulting in nearly no heat energy loss to the surrounding environment. $T_{a d}$ is the temperature at which the enthalpies of the products are equal to those of the reactants, which
Table 1. Thermodynamic parameters of reaction and production in the $\mathrm{NiO} / \mathrm{Al}$ system $[15,16]$

\begin{tabular}{lrccr}
\hline \hline & \multicolumn{1}{c}{$\mathrm{Al}$} & $\mathrm{NiO}$ & $\mathrm{Al}_{2} \mathrm{O}_{3}$ & \multicolumn{1}{c}{$\mathrm{Ni}$} \\
\hline$\Delta_{\mathrm{f}} \mathrm{H}^{\circ}(\mathrm{kJ} / \mathrm{mol})$ & 0 & -240.35 & -1675.7 & 0 \\
Melting point $(\mathrm{K})$ & 933 & 2257 & 2327 & 1728 \\
Boiling point $(\mathrm{K})$ & 2790 & $/$ & $/$ & 3156 \\
$\Delta \mathrm{H}^{\circ}{ }_{\text {liquid }}(\mathrm{kJ} / \mathrm{mol})$ & 10.56 & $/$ & -1620.57 & 17.48 \\
$\Delta \mathrm{H}^{\circ}{ }_{\text {gas }}(\mathrm{kJ} / \mathrm{mol})$ & 330.0 & $/$ & $/$ & 430.12 \\
\hline
\end{tabular}

can be written in a general form as:

$$
2 \mathrm{Al}+3 \mathrm{NiO}=\mathrm{Al}_{2} \mathrm{O}_{3}+3 \mathrm{Ni}
$$

The thermodynamic parameter of reaction and production in the NiO/Al system is shown in Table 1.

Suppose that the reaction is conducted under adiabatic conditions and completed by chemical stoichiometry. According to the first law of thermodynamics, the isobaric enthalpy of an isolated system is a constant, which means that the enthalpy of the reactants at temperature $T_{0}$ is equal to one of the reaction products at the adiabatic temperature, $T_{a d}$. The computational principle of determining $T_{\text {ad }}$ and the flowchart of the computer simulation program were the same as those used earlier [17]. The simulation program for the adiabatic temperature was compiled using the TurboC2 compiler; then the simulation reliability was verified by comparing these results with results in the literature $[18,19]$.

Different mass fractions of the diluent additives in raw materials can decrease not only the adiabatic temperature but also the combustion velocity, according to the theoretic principle of calculating the apparent activation energy. In order to measure the combustion velocity of

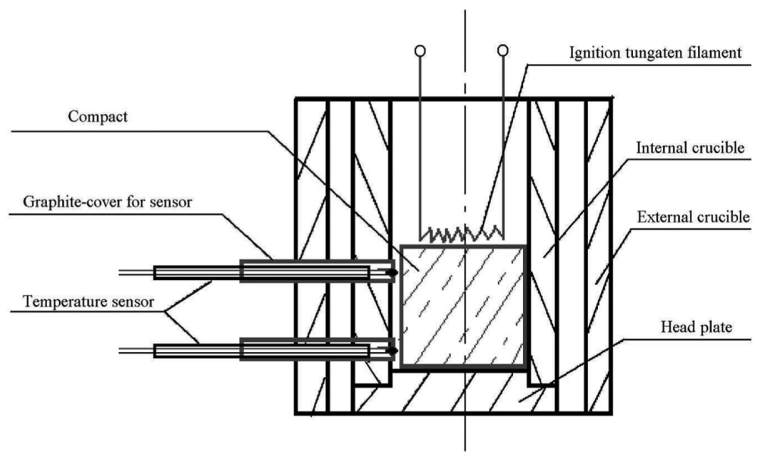

(a) Schematic diagram of velocity testing device

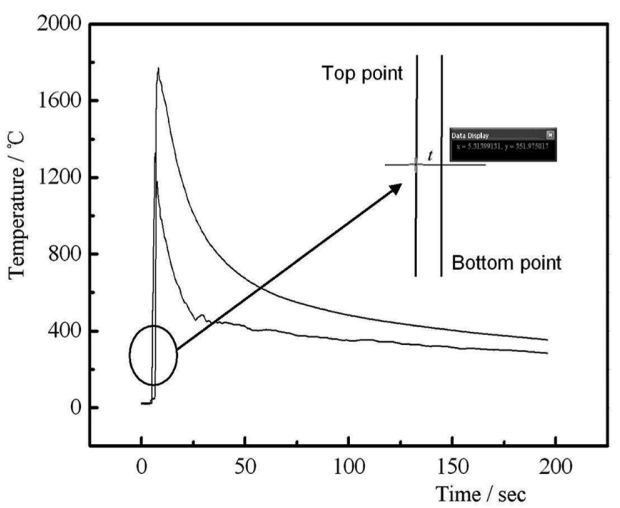

(b) Schematic diagram of velocity measurement

Fig. 1. Schematic of combustion velocity device and measurement. 
the compacts with different mass fractions of the diluent additives, the combustion velocity device and measurement method were designed as shown in Fig. 1. The present author and colleagues $[18,20]$ have already successfully investigated the combustion velocity of other compacts using this device.

Combining the kinetic equation with the Arrhenius combustion thermodynamic equation, Merzhanov et al. $[4,11]$ derived an equation to display the relationship between combustion velocity $\mathrm{v}$ and adiabatic temperature $T_{a d}$ in a static condition as:

$$
v^{2}=f(n) \frac{\alpha C_{p} R\left(T_{a d}\right)^{2}}{Q E} ; K_{0} \exp \left(-\frac{E}{R T_{a d}}\right)
$$

where $\alpha$ is thermal diffusivity, $\mathrm{f}(\mathrm{n})$ is a function for reaction order, $\mathrm{K}_{\mathrm{o}}$ is a constant, $\mathrm{C}_{\mathrm{p}}$ is heat capacity, $\mathrm{R}$ is gas constant, $\mathrm{Q}$ is heat of reaction, and $\mathrm{E}$ is apparent activation energy.

If we take the logarithm of both sides, the relationship between $\ln \left(v / T_{a d}\right)$ and $T_{a d}{ }^{-1}$ is almost linear and the apparent activation energy (E) is just the slope of the lines. The apparent activation energy of many combustion synthesis systems were obtained using this approach. For example, the apparent activation energy of Ti/B and Ti/C were calculated by Holt and Dunmead et al. and the combustion mechanisms were studied. Other studies (Choi et al. for $\mathrm{Ti} / \mathrm{C} / \mathrm{Fe}$ and $\mathrm{Ti} / \mathrm{C} / \mathrm{Co}$; Capaldi et al. for $\mathrm{Ti} / \mathrm{C} / \mathrm{Fe}$ ) have been reported during the past 20 years $[4,11$, $21,22]$. The results indicated that different apparent activation energies induced different combustion mechanisms.

\section{Results and Discussion}

\subsection{Adiabatic Temperature Calculation of the $\mathrm{NiO} /$}

\section{Al aluminothermic System}

The adiabatic temperature of the $\mathrm{NiO} / \mathrm{Al}$ system was calculated using the computer program as shown in Fig. 2. In the temperature range of preheating the reactants from $298 \mathrm{~K}$ to $2,790 \mathrm{~K}$, the adiabatic temperature of the $\mathrm{NiO} / \mathrm{Al}$ system remains the same $(3,156 \mathrm{~K})$ which is the boiling point of the Ni products. One fact can be draw from the calculation results is that below $2,790 \mathrm{~K}$, there is no effect from preheating the reactants, on the adiabatic temperature of the aluminothermic system. The other fact is that a gas phase of the Ni products exists (approximately 6.37\%) after combustion at a preheating

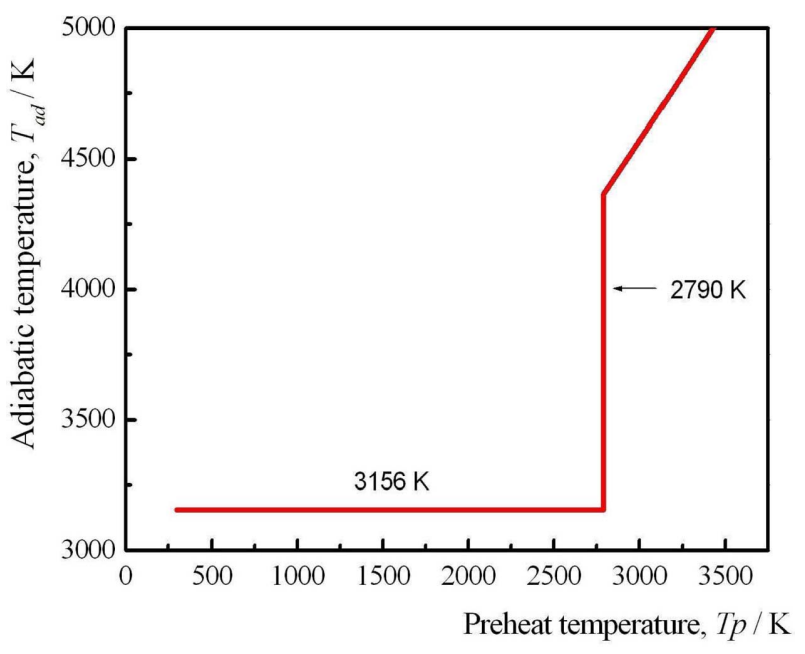

Fig. 2. Relationship between adiabatic temperature and preheating temperature in the $\mathrm{NiO} / \mathrm{Al}$ system.

temperature of $298 \mathrm{~K}$ [23].

In the process of simulation, if we ignore the vaporization enthalpy of the Ni products $\left(\Delta_{\mathrm{f}} \mathrm{H}_{\text {gas }}^{\circ}, 430.12 \mathrm{~kJ} / \mathrm{mol}\right)$, the adiabatic temperature will change to $3595.6 \mathrm{~K}$. This is very close to previously reported data [3]. Probably, the main reason for this significant discrepancy in the adiabatic temperature lies in whether the vaporization enthalpy of the $\mathrm{Ni}$ products is considered during computer simulations.

\subsection{Apparent Activation Energy Calculation of the NiO/Al Aluminothermic System}

The effects of different mass fractions of the $\mathrm{Al}_{2} \mathrm{O}_{3}$ diluent additives on the adiabatic temperature and combustion velocity are shown in Fig. 3(a). There is a remarkable corresponding variation trend between combustion velocity and adiabatic temperature. In certain ranges of $\mathrm{Al}_{2} \mathrm{O}_{3}$ addition (0-5 wt $\%$, and $\left.25-35 \mathrm{wt} \%\right)$, the combustion velocity of the $\mathrm{NiO} / \mathrm{Al}$ aluminothermic system shows the same variation trend as the adiabatic temperature, and the combustion is considerably homogenous.

The Arrhenius diagram curve of $\ln \left(\mathrm{v} / \mathrm{T}_{\mathrm{ad}}\right) \sim \mathrm{T}_{\mathrm{ad}}{ }^{-1}$ of the $\mathrm{NiO} / \mathrm{Al}$ system is shown in Fig. 3(b). The results indicated that different apparent activation energies will exist in different temperature ranges, which also displayed a different combustion mechanism. When the temperature is above the boiling point of the $\mathrm{Al}$ reactant $(2,790 \mathrm{~K})$, the apparent activation energy (E) of the $\mathrm{NiO} / \mathrm{Al}$ aluminothermic system is $64 \pm 14 \mathrm{~kJ} / \mathrm{mol}$. However, the apparent activation energy is $189 \pm 15 \mathrm{~kJ} / \mathrm{mol}$ when the temperature 


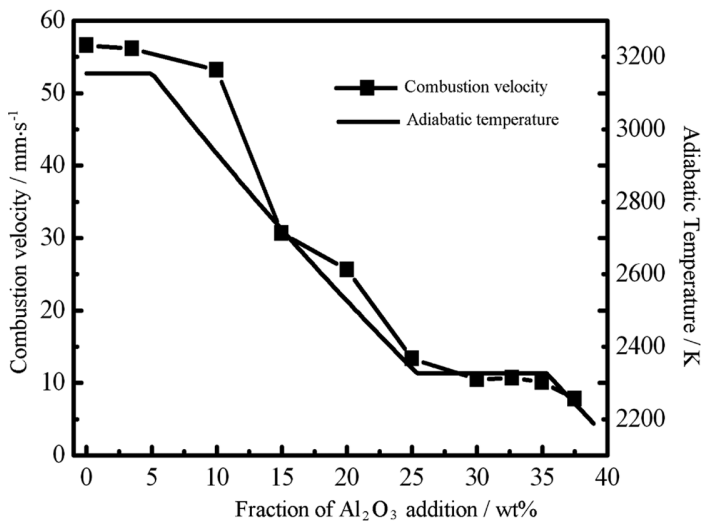

(a) Relationship between combustion velocity and fraction of diluent additive

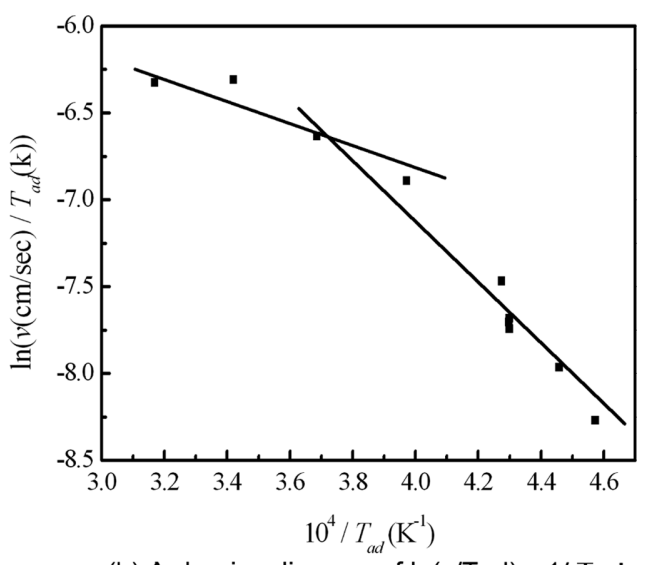

(b) Arrhenius diagram of $\ln (\mathrm{v} / \mathrm{Tad}) \sim 1 / \mathrm{Tad}$

Fig. 3. Apparent activation energy calculation for the NiO/Al system.

is below $2,790 \mathrm{~K}$.

Different combustion mechanisms operate in different temperature ranges (under or above 2,790 K). Because of low activation energy $(64 \pm 14 \mathrm{~kJ} / \mathrm{mol})$ at temperatures above $2,790 \mathrm{~K}$, the $\mathrm{Al}$ particles in raw materials will boil into the gas phase and quick mass-transfer occurs in the compact, which leads to severe and rapid combustion, high thermal energy generation, and high combustion temperature. In contrast, at low combustion temperatures (under 2,790 K); corresponding to high activation energy, the $\mathrm{Al}$ particles in raw materials exist in a liquid phase and slow mass-transfer occurs in the compact through capillary attraction to infiltrate the spaces between other particles. The conclusion is that the combustion process for the $\mathrm{NiO} / \mathrm{Al}$ aluminothermic system should be controlled by the alumina mass-transfer in the raw compact.

\subsection{Experimental Verification of the Results of the Apparent Activation Energy Calculation}

Analysis of combustion mechanisms indicated that the
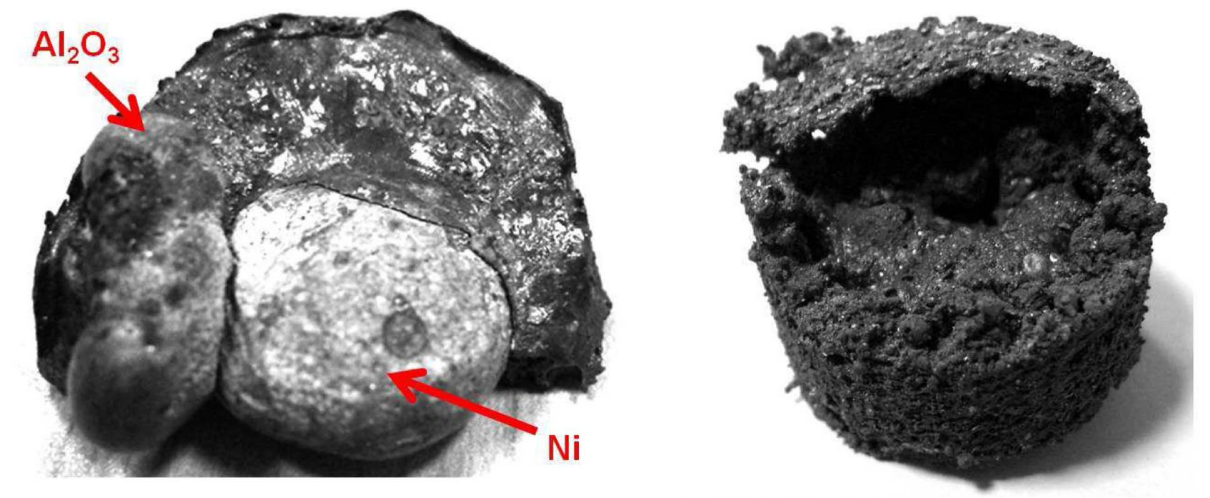

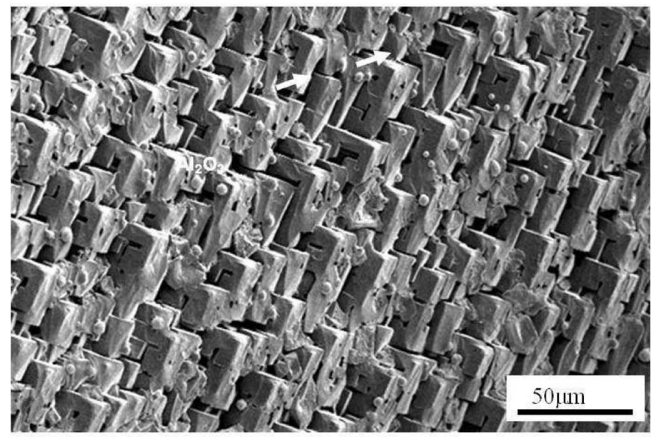

(a) $3 \%$ wt fraction of $\mathrm{Al}_{2} \mathrm{O}_{3}$ addition

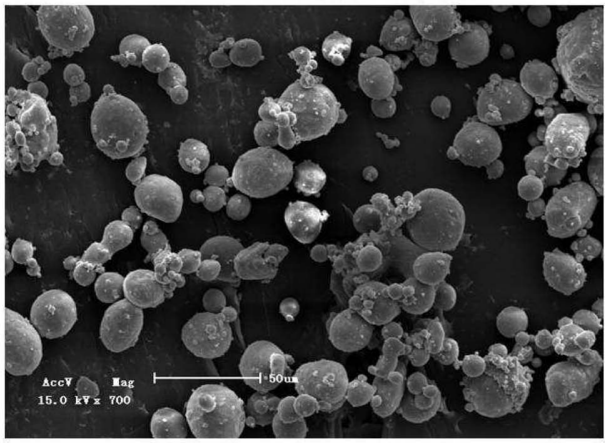

(b) $35 \%$ wt fraction of $\mathrm{Al}_{2} \mathrm{O}_{3}$ addition

Fig. 4. Experimental verification of the activation energy mechanism analysis of the $\mathrm{NiO} / \mathrm{Al}$ system. 
combustion process of the $\mathrm{NiO} / \mathrm{Al}$ system is controlled by the mass-transfer of $\mathrm{Al}$ particles in the raw materials of the thermit compact. A verification experiment was conducted using $\mathrm{Al}$ (purity $99.9 \%$, particulate size 100 $\mu \mathrm{m}$ ) powders and $\mathrm{NiO}$ (purity $99.99 \%$, particulate size 44 $\mu \mathrm{m})$ powders in the combustion synthesis system. The reactant powders were mixed by ball milling in ethanol with mass fractions of $\mathrm{Al}_{2} \mathrm{O}_{3}$ additions $3 \mathrm{wt} \%$ and 35 wt $\%$; corresponding to the adiabatic temperatures of $3,156 \mathrm{~K}$ and 2,723 K, respectively.

The dried reactant powders of $200 \mathrm{~g}$ were cold-pressed into a graphite crucible with an inner diameter of $30 \mathrm{~mm}$. The density of the powder compact was approximately $55 \%$ of the theoretical value. The thermite mixture was ignited using a W-coil by passing an electrical current through the mixture. The macro-shape and microstructure are displayed in Fig. 4.

As to the compact of $3 \mathrm{wt} \%$ fraction $\mathrm{Al}_{2} \mathrm{O}_{3}$ addition, because of combustion at high temperature $(3,156 \mathrm{~K}$ of adiabatic temperature), the activation energy is very low. The high thermal energy generation makes the $\mathrm{Al}_{2} \mathrm{O}_{3}$ diluent additives re-melt, and then crystallize with the $\mathrm{Al}_{2} \mathrm{O}_{3}$ products. The grain crystals are regular with little $\mathrm{Ni}$ product particles adhering to them, as shown in Fig. 4(a). However, the compact of $35 \mathrm{wt} \%$ fraction of $\mathrm{Al}_{2} \mathrm{O}_{3}$ addition has a different morphology in terms of not only macro- but also micro-structure of the final products, as shown in Fig. 4(b).

\section{Conclusion}

Based on thermodynamic theory and a computer simulation technique, the adiabatic temperature of the $\mathrm{NiO} / \mathrm{Al}$ aluminothermic system was calculated theoretically. Different mass fractions of the diluent additives in the raw materials can decrease not only the adiabatic temperature, but also the combustion velocity. Combining the results of the adiabatic temperature calculation, with variation of the combustion velocity with the mass-fraction of the diluting agent $\left(\mathrm{Al}_{2} \mathrm{O}_{3}\right)$ in the aluminothermic system, the apparent activation energy was measured by the Arrhenius diagram of $\ln \left(\mathrm{v} / \mathrm{T}_{\mathrm{ad}}\right)^{-1} / \mathrm{Tad}$ based on the combustion equation given by Merzhanov et al. The results indicated that different apparent activation energies exist within different temperature ranges, which also involved different combustion mechanisms. The apparent activation energies of the $\mathrm{NiO} / \mathrm{Al}$ aluminothermic system are $64 \pm 14 \mathrm{~kJ} / \mathrm{mol}$ and $189 \pm 15 \mathrm{~kJ} / \mathrm{mol}$ corresponding to above and below the boiling point of aluminum $(2,790 \mathrm{~K})$, respectively. The combustion process is controlled by masstransference of aluminum reactant of the burning compact. The reliability of the calculation results was finally verified experimentally.

\section{Acknowledgements}

This work was supported by a grant from the Fundamental R\&D Program for Core Technology of Materials (10037206) funded by the Ministry of Knowledge Economy, Korea. Y. P. Song acknowledges that this study was supported by a grant from the Postdoctoral Innovative program (201203101, 2013M531636), NSFC(51001111, 51372255, 51201173), Chinese National Fusion Project for ITER (NO. 2013GB110005), Program of "Twelfth Five-Year" National Science and Technology Support Plan (2011BAD12B02). This work was supported by the National Research Foundation of Korea(NRF) grant funded by the Korea government(MEST) (No. 20100026981).

\section{References}

[1] A. G. Merzhanov and I. P. Borovinskaya: Int. J. SelfPropag. High-Temp. Synth., 17 (2008) 242.

[2] H. C. Yi, J. J. Moore: J. Mater. Sci., 25 (1990) 1159.

[3] L. L. Wang, Z. A. Munir and Y. M. Maximov: J. Mater. Sci., 28 (1993) 3693.

[4] T. Wang, Y. X. Lu, M. L. Zhu and J. S. Zhang: Mater. Review, 14 (2000) 3.

[5] J. Pei, J. T. Li, R. Liang and K. X. Chen: Ceram. Inter., 35 (2009) 3269.

[6] J. Pei, J. T. Li, G. H. Liu and K. X. Chen: J. Alloys Comp., 476 (2009) 854.

[7] J. Pei, J. H. Yang, L. Mei and J. T. Li: J. China Ceram. Soc., 37 (2009) 1669.

[8] D. Vrel, A. Hendaouri, P. Langlois, S. Dubois, V. Gauthier and B. Cochepin: Int. J. Self-Propag. High-Temp. Synth., 16 (2007) 62.

[9] V. N. Sanin, V. I. Yukhvid, A. E. Sytschev and N.V. Sachkova: Microgravity Sci. Tech., 22 (2010) 53.

[10] V. N. Sanin, V. I. Yukhvid, A. E. Sytschev, N.V. Sachkova and M. Y. Shiryaeva: Inorg. Mater., 45 (2009) 635.

[11] S. Yin: Combustion Synthesis, Beijing: Metallurgic Industry Press, 2004 (in Chinese). 
[12] D. Q. Wang: J. Eur. Ceram. Soc., 29 (2009) 1485.

[13] P. J. C. M. Li and C.T. Liu: Mater. Sci. and Eng. A, 357 (2003) 248.

[14] B. Rupp, J. B. Holt and J. Wong: Calphad, 16 (1992) 377.

[15] http://webbook.nist.gov

[16] D. L. Ye: Practical Thermodynamics Data Manual of inorganics. Beijing: Metallurgic Industry Press, 1981 (in Chinese)

[17] Y. P. Song, H. S. Kim, C. S. Lee, J. T. Li and J. Pei: Mater. Trans., 12 (2010) 2230.

[18] Y. P. Song, Calculation of Adiabatic Temperature and Process Simulation of Ceramic Materials via Thermite Combustion synthesis under Ultra-High Gravity Field, Postdoctoral thesis, Technical Institute of Physics and
Chemistry, Chinese Academy of Sciences (2009) (in Chinese).

[19] W. W. Ji, Y. P. Song and Y. Yang: Bul. Chin. Ceram. Soc., 28 (2009) 1300.

[20] Y. P. Song, J. T. Li, Z. M. Lin and J. Pei: J. China Ceram. Soc., 37 (2009) 214.

[21] J. C. Lasalvia and M. A. Meyers: Metal. Mater. Trans. A, 26 (1995) 3011.

[22] J. B. Holt, D. D. Kingman and G. M. Bianchini: Mater. Sci. Eng. A, 71 (1985) 321.

[23] Y. P. Song, J. T. Li, J. Pei and W. W. Ji: Acta Mater. Comp. Sinica, 27 (2010) 134. 